\title{
In memoriam Jürg Hegglin
}

Am 21. Dezember 2016 ist Dr. med. Jürg Robert Hegglin einen Tag vor seinem 80. Geburtstag an seinem Wohnort verstorben.

Während des Studiums haben wir ihn zuerst als Ausbildner im chirurgischen Untersuchungskurs und später während der Assistentenzeit als Chefarzt kennen und sehr schätzen gelernt.

\section{Jürg Hegglin war mit Leib und Seele Chirurg.}

Jürg Hegglin wurde am 22. Dezember 1936 als Sohn des berühmten Internisten Prof. Dr. Robert Hegglin in Zürich geboren. Anders als sein Vater wandte er sich nach dem Staatsexamen in Zürich im Anschluss an ein Basisjahr am Pathologischen Institut St. Gallen umgehend der Chirurgie zu. Er erhielt eine profunde und breite Ausbildung in Allgemeiner Chirurgie bei den Chirurgie-Grössen seiner Zeit: Prof. Martin Allgöwer, Åke Senning, Aristakes Akovbiantz und Georges Mayor. Sein Curriculum als Allgemeinchirurge im sehr weit gefassten Sinn hat er mit einem Jahr Gynäkologie an der Pflegerinnenschule in Zürich bei Frau Dr. Ehrat abgerundet. Nach einem IKRK-Einsatz als Chefarzt in Biafra wurde Jürg Hegglin Chirurgie-Oberarzt im Stadtspital Waid in Zürich, wo er gerne seinem Lehrauftrag für Chirurgie der Universität Zürich nachkam. Dieser veranlasste ihn zur Herausgabe des Buches Chirurgische Untersuchung, welches in mehrere Sprachen übersetzt und mehrfach aufgelegt wurde. Auch in Zeiten zunehmender Technisierung der medizinischen Diagnostik lag ihm die klassische klinische Untersuchung des Patienten am Krankenbett sehr am Herzen; dies nicht nur aus Gründen des Kostenbewusstseins, sondern vor allem zur Förderung einer guten Patienten-Arzt-Beziehung.

\section{Viele seiner Schüler blieben ihm bis in sein hohes Alter freundschaftlich verbunden.}

Mit einem prallen Rucksack wurde er im Jahre 1975 zum Chefarzt im Spital Richterswil am Zürichsee ernannt, wo er bis zum Ende seiner chirurgischen Laufbahn tätig blieb.

Jürg Hegglin war mit Leib und Seele Chirurg. So erstaunt es nicht, dass er vielen Studenten in den klinischen Semestern anlässlich des chirurgischen Untersuchungskurses und in "seinem Spital» als Chef und begeisterter Lehrer in unvergesslicher Erinnerung bleibt. Seine markigen, humorvollen Aussagen lösen auch heute noch ein Schmunzeln aus.

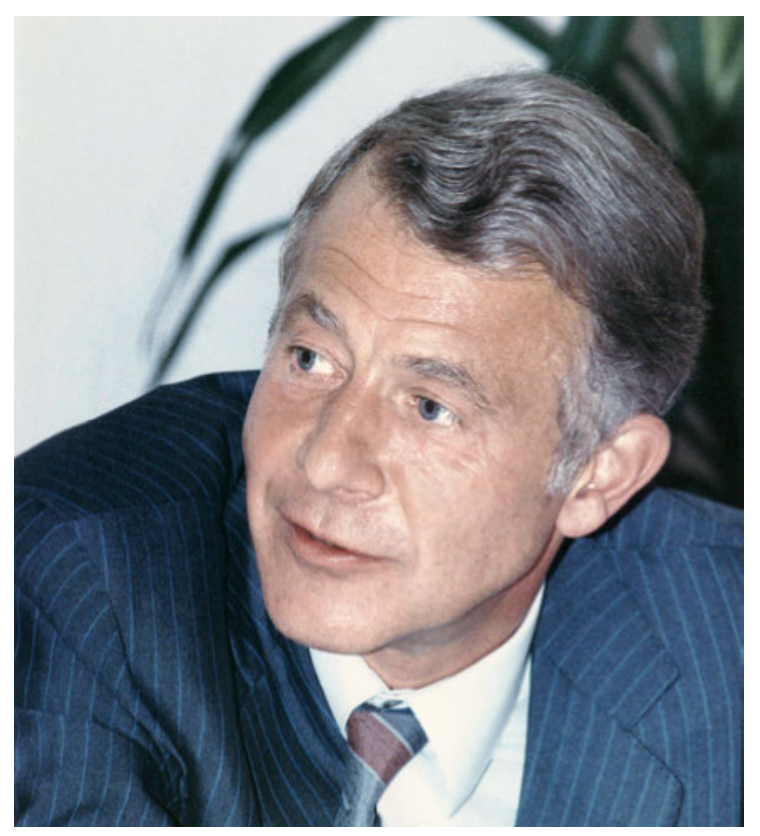

Dr. med. Jürg Hegglin (1936-2016).

Viele seiner Schüler blieben ihm bis in sein hohes Alter freundschaftlich verbunden, und er verfolgte ihre Karrieren aufmerksam und kritisch. Wir wurden einer harten, aber fairen Schule unterzogen. Unaufmerksamkeit am Operationstisch setzte er fehlendem Interesse gleich und gab dies mit seiner meist sehr direkten Art unmissverständlich zu verstehen. Seinem Ärger über administrativen Unsinn konnte er sich durchaus mit despektierlichen Bemerkungen über den Spitalverwalter Luft verschaffen - allenthalben sehr zum Vergnügen seiner ganzen Mannschaft. Im Operationssaal und auf Chefvisite liess er oft den für ihn charakteristischen Schalk in seinen Augen aufblitzen und sorgte damit für Auflockerung und wohltuende Heiterkeit. Dank seinem feinfühligen Humor, seiner Begeisterung und seiner Fähigkeit zur Selbstkritik blicken wir gerne auf eine intensive, lehrreiche und auch unterhaltsame Assistenzzeit zurück.

Auch nach Aufgabe seiner beruflichen Tätigkeit blieb Jürg Hegglin vielseitig kulturell und politisch interessiert. Dies erlaubte ihm, sich seiner zweiten grossen Passion - dem Klavierspiel - mit voller Aufmerksamkeit zu widmen.

Seine charismatische Persönlichkeit behalten wir gerne in bester und liebevoller Erinnerung.

Madeleine Bardola-Furrer und Claude-André Chételat 